\title{
ANÁLISIS SOCIODEMOGRÁFICO DE LOS GRUPOS DE RIESGO EN CASTILLA Y LEÓN: LAS PERSONAS CON DISCAPACIDAD
}

\author{
Luis Carlos MARTÍNEZ FERNÁNDEZ \\ Universidad de Valladolid
}

RESUMEN: Casi seis de cada cien castellanos y leoneses son discapacitados. Representan un colectivo poblacional con una seria problemática en lo que se refiere a su integración en la sociedad. Para luchar contra estos desajustes, los poderes públicos competentes desarrollan un conjunto de políticas y actuaciones cuyos primeros resultados son esperanzadores.

PALABRAS CLAVE: Población, discapacidad, Castilla y León, inserción social.

ABSTRACT: Six per cent inhabitants of Castilla y León (España) have some handicap. It is a population group with a serious problems regarding their integration in the society. To fight against these imbalances the public administration is developing a group of political plans which first results are encouraging.

KEY WORDS: Population, handicap, Castilla y León, integration in the society.

RÉSUMÉ: D' après les statistiques, six de chaque cent habitants de la Communauté Autonome de Castilla y León (España) ont quelque sorte de discapacité. Ils répresentent un secteur de population avec une sérieuse problematique en ce qui concerne à sa integration sociale. Por s'attaquer à ces désajustements, les pouvoirs publiques on pris des mesures dont les premiers résultats sont encourageants.

MOTS CLÉ: Population, discapacité, Castilla y León, integration sociale.

RESUMO: Quase seis de cada cem castelhanos e leoneses são incapacitados. Representam un colectivo populacional com uma séria problemática no que se refere à sua integração social. Para lutar contra estes desajustes, os poderes públicos competentes desenvolvem um conjunto de políticas cujos primeiros resultados são esperançosos.

PALAVRAS CLAVE: População, incapacidad, Castilla y León, integração social.

La Unión Europea en su Decisión de 3 de diciembre de 2001 declaró el año 2003 como Año Europeo de las Personas con Discapacidad, al cumplirse el décimo aniversario de la adopción por la Asamblea General de las Naciones Unidas de las Normas Uniformes sobre Igualdad de Oportunidades para las Personas Discapacitadas. Entre los propósitos de esta Decisión se encuentra el desarrollo de acciones tendentes a garantizar una mejor integración de estas personas en todos los ámbitos de la vida, a través de programas de sensibilización a

\footnotetext{
* Quisiera mostrar mi agradecimiento a los profesores Pedro Caballero Fernández-Rufete y José María Delgado Urrecho, compañeros y amigos, de quienes he aprendido todo lo que sé sobre demografía geográfica, por sus valiosas sugerencias y ayudas en la realización de este trabajo.
} 
la sociedad sobre derechos, necesidades y posibilidades de la población minusválida.

En este contexto general es en el que pretende enmarcarse este estudio. Un trabajo que tiene por objetivo fundamental el diagnóstico de la realidad sociodemográfica actual de la población minusválida castellana y leonesa, haciendo un especial hincapié en la problemática ligada a la difícil inserción de este colectivo en la sociedad.

Esta finalidad obedece a la convicción de que es preciso conocer para actuar $\mathrm{y}$, por tanto, que estudios como el presente puedan servir de base al amplio elenco de políticas sociales e instrumentos públicos destinados a garantizar el bienestar y la calidad de vida a las personas que por razones sobreimpuestas padecen algún tipo de discapacidad física, psíquica o sensorial. No en vano, siguiendo las palabras del profesor Ortega Valcárcel, la Geografía puede entenderse como una disciplina social orientada a los problemas relevantes de nuestro tiempo (Ortega, 2000, 540-543) ${ }^{1}$. En una sociedad como la nuestra, la discapacidad sobrevenida a una parte minoritaria, pero importante, de la población es uno de ellos.

\section{LAS PERSONAS DISCAPACITADAS EN CASTILLA Y LEÓN. CUANTÍA, CARACTERES ESTRUCTURALES Y DISTRIBU- CIÓN ESPACIAL.}

\section{Un colectivo de apreciable entidad.}

Según la Base de Datos de Reconocimiento de Minusvalía de la Gerencia de Servicios Sociales de la Junta de Castilla y León, 145.326 personas presentaban, en 1999, un grado de deficiencia igual o superior al $33 \%{ }^{2}$. Para el mismo año, el Instituto de Migraciones y Servicios Sociales, en su Base de Datos Estatal de Personas con Discapacidad, cifraba en 1.255.798 el número de españoles que habían obtenido esa misma calificación de minusvalía.

Estas sumas manifiestan, en una primera valoración, que un 5,84\% de los 2.488.062 de castellanos y leoneses, que aparecen recogidos en la Revisión del

\footnotetext{
${ }^{1}$ En este sentido, hay que destacar los estudios realizados recientemente por geógrafos sobre algunos colectivos poblacionales de indudable interés sociodemográfico en Castilla y León. Como el dirigido por Lorenzo López Trigal y José María Delgado Urrecho, referente a la población inmigrante (LóPEZ y DELGADo, 2002) o el dirigido por Pedro Caballero Fernández-Rufete y José María Delgado Urrecho acerca de las personas mayores (CABALlero y Delgado, 2003).

${ }^{2}$ Colectivo que ascendía, en diciembre de 2001, a 159.619 personas, según los datos parciales publicados por el Ministerio de Trabajo y Asuntos Sociales en la Base Estatal de Personas con Discapacidad.
} 
Padrón Municipal de Habitantes a 1 de enero de 1999, son personas con discapacidad. Un porcentaje que reviste aún más importancia si se tiene en cuenta que en el conjunto del estado español los discapacitados representan el 3,12\% de la población nacional y, por comunidades autónomas, únicamente, el Principado de Asturias (8,37\%) y Extremadura (6,43\%) presentan unas tasas en sus relaciones entre población con discapacidad y total de habitantes más elevadas que Castilla y León.

Tanto en el caso del Principado de Asturias como en el propio de Castilla y León, y también, aunque a tenor de los resultados, en menor medida, en el de Extremadura, la mayor importancia proporcional del contingente de personas minusválidas debe relacionarse, en primera instancia, con el rasgo demográfico fundamental que caracteriza a estas regiones, y éste no es otro que el envejecimiento de su población ${ }^{3}$.

\section{Las estructuras por edad, sexo y tipo de discapacidad.}

En efecto, como se puede observar a través de las pirámides poblacionales (FIGURA 1) y, más claramente, a la luz de las estadísticas (CUADRO 1), Castilla y León es una región envejecida. Por un lado, en la cúspide, el 21,92\% de sus habitantes son ancianos, en el extremo opuesto, en la base, el 13,54\% de los castellanos y leoneses tienen menos de 16 años. Tal situación supone que casi hay dos personas mayores de 65 años por cada joven (1,62 exactamente) y que la edad media de la población regional sea de 42,9 años. Ello, unido a que el porcentaje de personas discapacitadas aumenta considerablemente con la edad, desde el $1,21 \%$ de los jóvenes al $12,75 \%$ de las personas ancianas, pasando por un $4,46 \%$ de los adultos (de 16 a 64 años), explicaría, en buena medida, ese vínculo existente entre envejecimiento y discapacidad.

Una relación todavía más estrecha habida cuenta de la particular estructura por edades de la población minusválida, con un $47,85 \%$ de ancianos y un escaso $2,82 \%$ de menores de 16 años. Lo que conlleva que el índice de envejecimiento sea de casi diecisiete personas mayores $(16,96)$ por cada joven con discapacidad y que la edad media de este colectivo se sitúe en 60,4 años.

Como primera consecuencia del fuerte envejecimiento de la población discapacitada, el grado de feminización es el principal atributo de este colectivo a la hora de atender a su distribución por sexos (FIGURA 1 y CUADRO 2).

\footnotetext{
${ }^{3}$ A tenor de los indicadores de estructura demográfica por edad, el Principado de Asturias, Castilla y León y Extremadura ocuparían los puestos primero, segundo y undécimo, respectivamente, del ranking de envejecimiento por comunidades autónomas (CABALLERO y DELGADO, 2003, 41).
} 
Figura 1. Pirámides de población total y de población discapacitada de Castilla y León, 1999.
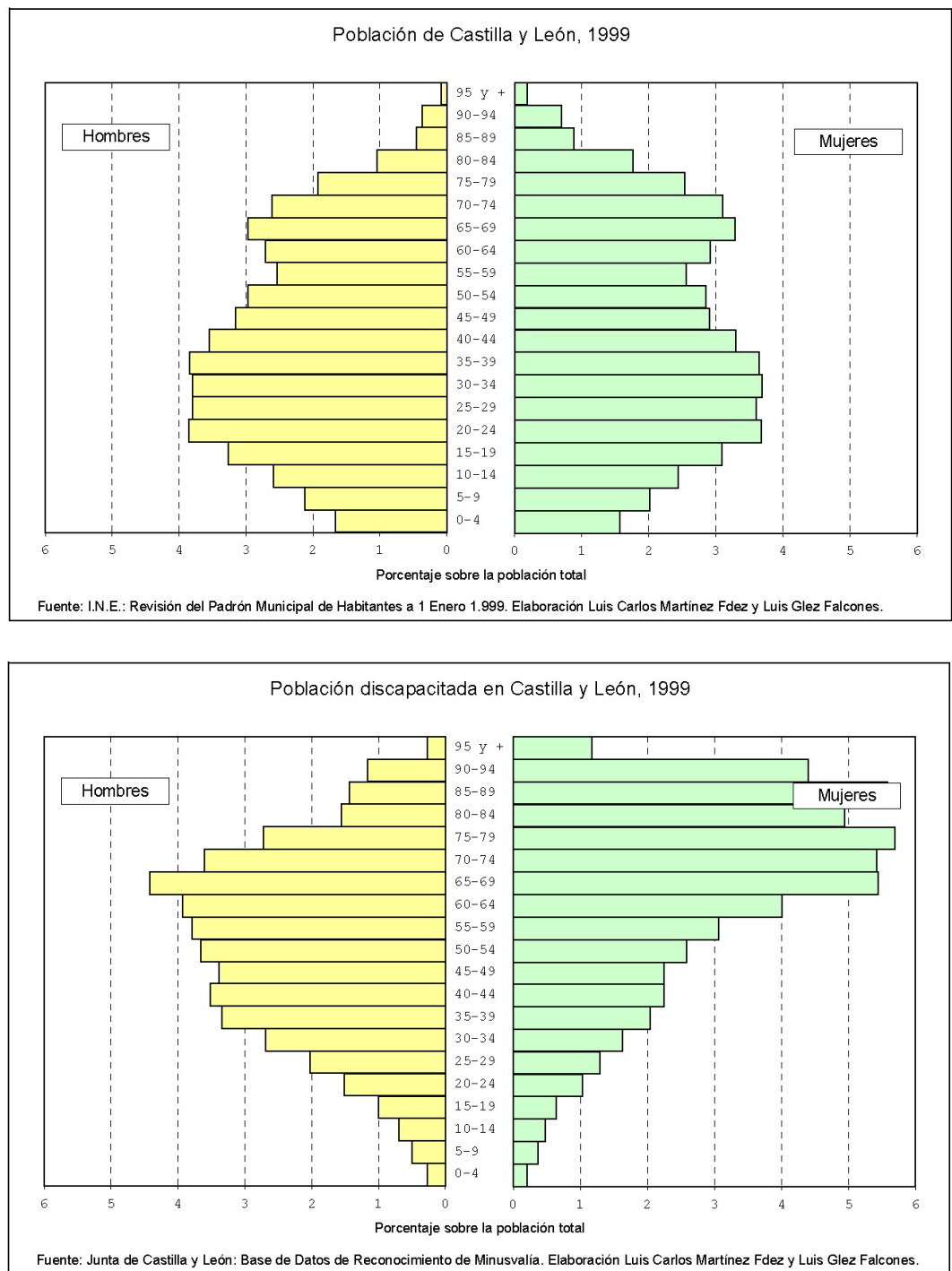
Cuadro 1. Comparación de las estructuras demográficas por edad de la población con discapacidad de Castilla y León respecto al total de población regional. 1999

\begin{tabular}{lrrr}
\hline Grupos de edad & Población total & $\begin{array}{r}\text { Población con dis- } \\
\text { capacidad }\end{array}$ & $\begin{array}{r}\% \text { de población dis- } \\
\text { capacitada }\end{array}$ \\
\hline \multirow{2}{*}{ Jóvenes (\%) } & 336.795 & 4.101 & 1,21 \\
& $(13,54)$ & $(2,82)$ & \\
Adultos (\%) & 1.605 .893 & 71.685 & 4,46 \\
\multirow{2}{*}{ Ancianos $(\% 9$} & $(64,54)$ & $(49,33)$ & 12,75 \\
& 545.374 & 69.540 & $(47,85)$ \\
\multirow{2}{*}{ Total } & $(21,92)$ & 145.326 & 5,84 \\
\hline
\end{tabular}

FUENTES: I.N.E.: Revisión del Padrón de Habitantes a 1 de enero de 1999 y JUNTA DE CASTILla y LeÓn: Base de Datos de Reconocimiento de Minusvalía, 1999.

Cuadro 2. Estructuras demográficas por sexo, en grupos de edad, de la población con discapacidad en Castilla y León y de la población regional total. 1999

\begin{tabular}{lrrrr}
$\begin{array}{l}\text { Grupos de } \\
\text { edad }\end{array}$ & $\begin{array}{r}\text { Castilla y León } \\
\text { Hombres (\%) }\end{array}$ & $\begin{array}{r}\text { Castilla y León } \\
\text { Mujeres (\%) }\end{array}$ & $\begin{array}{r}\text { Población dis- } \\
\text { capacitada } \\
\text { Hombres (\%) }\end{array}$ & $\begin{array}{r}\text { Población dis- } \\
\text { capacitada } \\
\text { Mujeres (\%) }\end{array}$ \\
\hline \multirow{2}{*}{ Jóvenes } & 173.242 & 163.553 & 2.413 & 1.688 \\
\multirow{2}{*}{ Adultos } & $(51,44)$ & $(48,56)$ & $(58,84)$ & $(41,16)$ \\
& 818.340 & 787.553 & 41.657 & 30.028 \\
\multirow{2}{*}{ Ancianos } & $(50,96)$ & $(49,04)$ & $(58,11)$ & $(41,89)$ \\
& 235.574 & 309.800 & 22.076 & 47.464 \\
\multirow{2}{*}{ Total } & $(43,19)$ & $(56,81)$ & $(31,75)$ & $(68,25)$ \\
\hline & 1.227 .156 & 1.260 .906 & 66.146 & 79.180 \\
& $(49,32)$ & $(50,68)$ & $(45,52)$ & $(54,48)$ \\
\hline
\end{tabular}

FUENTES: I.N.E.: Revisión del Padrón de Habitantes a 1 de enero de 1999 y JuNTA DE CASTILla y LeÓN: Base de Datos de Reconocimiento de Minusvalía, 1999.

Cuadro 3. Tipos de discapacidad y población afectada. 1999

\begin{tabular}{lrr}
\hline $\begin{array}{l}\text { Tipo de } \\
\text { discapacidad }\end{array}$ & $\begin{array}{r}\text { Porcentaje sobre el total } \\
\text { de población discapacita- } \\
\text { Personas afectadas }\end{array}$ \\
\hline Física & 91.406 & 62,89 \\
Psíquica & 33.138 & 22,80 \\
Visual & 14.588 & 10,03 \\
Auditiva & 6.194 & 4,26 \\
\hline Total & 145.326 & 100 \\
\hline
\end{tabular}

Fuente: JunTA De CASTILla Y LEÓn: Base de Datos de Reconocimiento de Minusvalia, 1999. 
En términos generales, los varones representan el 45,52\% de los minusválidos mientras que el porcentaje de féminas aumenta hasta el 54,48\%, dándose una relación de 0,83 hombres por cada mujer discapacitada $(0,97$ para el total de población de Castilla y León). Por cohortes etáreas, como ocurre, aunque más matizadamente, para el conjunto de población castellana y leonesa, los desequilibrios entre géneros son favorables a las mujeres a medida que se avanza en edad, dada su mayor esperanza de vida. Así, el porcentaje de hombres sobre el de mujeres con discapacidad es considerablemente más elevado en las generaciones de jóvenes y de adultos ( $54,84 \%$ y $54,11 \%$, respectivamente) tornándose la balanza en el tramo correspondiente a las personas de más de 65 años, que presentan unas tasas mucho más favorables al colectivo femenino, el $68,25 \%$ de las personas ancianas discapacitadas.

Pero además, esta senescencia que caracteriza a la población minusválida influye, también, en su estructura por tipos de discapacidad (CUADRO 3). En este sentido, a falta de datos más concisos sobre la representación de las distintas tipologías por grupos de edad, se puede apuntar este hecho, como causa principal, en la explicación de que los mayores porcentajes de discapacitados se asocien a tipos de minusvalías físicas y psíquicas $(62,89$ y $22,80 \%$, respectivamente). No olvidando que, aún creciendo las posibilidades de sufrir pérdidas de visión o audición con los años, las lesiones sensoriales con un grado superior al $33 \%$ son más generalizables al conjunto de la población, independientemente de la edad (FERNÁNDEZ-MAYORALAS, ABELLÁN, RODRÍGUEZ y ROJO, 1993).

\section{La distribución territorial en función del tipo de municipio.}

El envejecimiento es un rasgo estructural, fundamental y desencadenante, en un colectivo que, como realidad demográfica que es, posee también una dimensión territorial, que hay que enfatizar. Así, la distribución de las personas minusválidas dentro de la región está condicionada, en cierta forma, por la trayectoria y las características de los distintos espacios. Siendo muy ilustrativo detenerse brevemente en estudiar los datos disponibles en función del tipo de muni$\mathrm{cipio}^{4}$, estableciendo una primera y básica distinción entre el ámbito rural, municipios de hasta 10.000 habitantes, y el urbano (CUADRO 4).

De este modo, se puede comenzar señalando que la mayor proporción de castellanos y leoneses que presentan alguna discapacidad viven en municipios rurales, concretamente el 58,25\%. El 41,75\% restante habita en ciudades peque-

\footnotetext{
${ }^{4}$ Para ello, se han utilizado los datos que aporta el Instituto Nacional de Estadística en la Encuesta sobre discapacidades, deficiencias y estado de salud. Si bien, estas cifras están referidas al conjunto de personas que presentan alguna minusvalía (275.299), independientemente del grado de ésta.
} 
ñas $(9,57 \%)$ o en las ciudades medias y grandes de la región (32,18\%), ámbitos donde se concentran los mayores porcentajes de población regional, el 54,46\%. Ello quiere decir que mientras la población de Castilla y León es en mayor medida urbana, son las áreas rurales las que presentan unas tasas más altas de personas discapacitadas en relación con su población, exactamente del 14,15\%, 3,09 puntos por encima de la media regional y muy superiores al $8,46 \%$ de las urbanas. Y es que, si la importancia relativa de las personas mayores es el rasgo que mejor define a la población de Castilla y León y ancianas son, todavía en mucha mayor medida, las personas discapacitadas, no es de extrañar que éstas habiten mayoritariamente en los núcleos rurales regionales (CUADRO 5), precisamente aquellos en los que el envejecimiento se presenta de manera especialmente significativa (CABALLERO, 2002).

Cuadro 4. Reparto de la población y de las personas con alguna discapacidad según el tamaño de los municipios. 1999

\begin{tabular}{lrrrrr}
\hline $\begin{array}{l}\text { Tamaño de } \\
\text { municipios }\end{array}$ & $A$ & $B$ & $C$ & $D$ & $E$ \\
\hline Hasta 10.000 hab. & 1.133 .211 & 45,54 & 160.369 & 14,15 & 58,25 \\
10.001- 50.000 hab. & 312.138 & 12,55 & 26.350 & 8,44 & 9,57 \\
50.001 hab. y más & 1.042 .713 & 41,91 & 88.580 & 8,49 & 32,18 \\
\hline Castilla y León & 2.488 .062 & 100 & 275.299 & 11,06 & 100 \\
\hline
\end{tabular}

A, Población; B, \% respecto a la población regional; $C$, Personas con alguna discapacidad; $D$, \% de discapacitados sobre la población del conjunto de municipios; $E$, \% sobre el total de personas con alguna discapacidad

FUENTES: I.N.E.: Revisión del Padrón de Habitantes a 1 de enero de 1999 e I.N.E.: Encuesta sobre discapacidades, deficiencias y estado de salud, 1999.

Cuadro 5. Distribución de las personas mayores de 65 años con alguna discapacidad en razón del tamaño del municipio donde residen. 1999

\begin{tabular}{|c|c|c|c|c|}
\hline Grupos de edad & $\begin{array}{r}\text { Hasta } 10.000 \\
\text { hab. }\end{array}$ & $\begin{array}{r}10.001 \mathrm{a} \\
50.000 \mathrm{hab} .\end{array}$ & $\begin{array}{r}50.001 \text { hab. y } \\
\text { más }\end{array}$ & Total \\
\hline Mayores de 65 años & $\begin{array}{r}115.328 \\
(60,36 \%)\end{array}$ & $\begin{array}{r}18.501 \\
(9,68 \%)\end{array}$ & $\begin{array}{r}57.257 \\
(29.96 \%)\end{array}$ & 191.087 \\
\hline
\end{tabular}

FUENTE: I.N.E.: Encuesta sobre discapacidades, deficiencias y estado de salud, 1999. 


\section{CONDICIONES DE VIDA E INTEGRACIÓN EN LA SOCIEDAD DE LA POBLACIÓN CON DISCAPACIDAD.}

Si todos estos rasgos estructurales y territoriales manifiestan el "significado demográfico" de los 145.326 castellanos y leoneses que han sido catalogados como minusválidos (275.299 teniendo en cuenta a toda la población que sufre alguna deficiencia, ¿qué decir de su importancia cualitativa?. En su valoración ha de adentrarse en el conocimiento de los aspectos más cotidianos de sus vidas, lo que se podría denominar las "condiciones sociales" de las personas con discapacidad en Castilla y León.

\section{El entorno social inmediato y las relaciones de dependencia.}

El ámbito más próximo de las relaciones sociales lo constituye la familia, entendiéndose ésta en un sentido laxo del término. La mayor o menor calidad de vida de las personas discapacitadas está condicionada, en primer instancia, por la convivencia en un entorno más o menos afectivo. En este sentido, la estructura de los hogares por tamaño predominante, tanto en términos absolutos como relativos, es la de dos personas, seguida por la de tres y la unipersonal (CUADRO 6). Por grandes grupos de edad, el hogar de dos personas es el más imperante entre la población anciana $(48,84 \%)$, por encima del unipersonal $(21,47 \%)$. Éste último, está relacionado, en mayor medida, más con la vejez y la soledad que con el grado de dependencia del minusválido, ya que sólo el 4,30\% de las personas con alguna deficiencia menores de 65 años viven solas. Entre las generaciones jóvenes y adultas el tamaño del hogar es esencialmente de tres y cuatro individuos.

Relacionado en cierta medida con lo anterior, las formas de convivencia dominantes entre las personas minusválidas dependientes ${ }^{5}$, deducidas a partir de la relación del cuidador principal con la persona que sufre alguna discapacidad, es la de pareja (CUADRO 7). En el caso de la población menor de 65 años es evidente está prevalencia (10,62\% de los casos) por el peso de las cohortes de edad adulta, conviviendo el minusválido con el cónyuge de edad similar y con uno o dos hijos, que aunque no se ocupen en exclusiva de los cuidados asistenciales completarían ese hogar tipo de tres o cuatro personas. Por su parte, la relevancia de la atención por parte de las madres ( $8,70 \%$ de las situaciones) se explicaría por la dedicación que prestan a sus hijos discapacitados jóvenes y adultosjóvenes solteros, con ayuda de forma secundaria de sus parejas y algún otro hijo, viviendo todos en un hogar de tres o cuatro personas.

${ }^{5}$ Como se puede apreciar en la tabla de datos número nueve, de las 275.299 personas que el I.N.E., en su Encuesta sobre discapacidades, deficiencias y estado de salud, considera que tienen alguna deficiencia, 108.456 son realmente dependientes. 
Cuadro 6. Personas con alguna discapacidad y tamaño del hogar. 1999

\begin{tabular}{lrrrrrrr}
\hline & & \multicolumn{6}{c}{ Tamaño del hogar $\left(n^{\circ}\right.$ personas $)$} \\
\cline { 3 - 9 } $\begin{array}{l}\text { Grupos de } \\
\text { edad }\end{array}$ & Total & 1 & 2 & 3 & 4 & 5 & 6 y más \\
\hline$<65$ años & 84.212 & 3.621 & 14.619 & 24.093 & 23.999 & 11.269 & 6.611 \\
$>65$ años & 191.087 & 41.025 & 93.321 & 28.859 & 12.448 & 8.077 & 7.357 \\
\hline Totales & 275.299 & 44.646 & 107.940 & 52.952 & 36.447 & 19.346 & 13.968 \\
\hline
\end{tabular}

FUENTE: I.N.E.: Encuesta sobre discapacidades, deficiencias y estado de salud, 1999.

Cuadro 7. Personas con alguna deficiencia y relación del cuidador con la persona con discapacidad

\begin{tabular}{lrrrrrrrr}
\hline & $A$ & $B$ & $C$ & $D$ & $E$ & $F$ & $G$ & $H$ \\
\hline$<65$ años & 8.942 & 3.275 & 551 & 875 & 547 & 7.325 & 800 & 592 \\
$>65$ años & 23.851 & 29.015 & 5.641 & 2.063 & 579 & 0 & 0 & 9.120 \\
Total & 32.793 & 32.290 & 6.192 & 2.938 & 1.126 & 7.325 & 800 & 9.712 \\
\hline \multicolumn{2}{c}{$I$} & & $J$ & $K$ & $L\left(^{*}\right)$ & $M$ & & \\
\hline$<65$ años & 1.271 & 1.467 & 299 & 58.268 & 84.212 & & \\
$>65$ años & 7.561 & 3.884 & 798 & 108.575 & 191.087 & & & \\
\hline Total & 8.832 & 5.351 & 1.097 & 166.843 & 275.299 & & &
\end{tabular}

A, Cónyuge; B, Hija; C, Hijo; D, Hermana; E, Hermano; F, Madre; G, Padre; H, Otro pariente; I, Empleado, amigo o vecino; J, Servicios sociales; K, Otra relación; L, No consta; M, Total

(*)A pesar del elevado número de personas con alguna deficiencia para las que "no consta" la relación del cuidador con la persona con discapacidad, se toman los datos contenidos en la tabla como la única aproximación posible para el estudio de esta realidad.

FUENTE: I.N.E.: Encuesta sobre discapacidades, deficiencias y estado de salud, 1999.

En cuanto a la población mayor de 65 años, las ayudas provienen, en la mayor parte de las ocasiones $(15,18 \%)$, de las hijas, fundamentalmente solteras y, con ello, inquilinas del hogar familiar, dedicadas en gran medida al cuidado de un único progenitor viudo. En otras circunstancias (12,48\%) son los cónyuges los que se ocupan de las personas minusválidas ancianas. En ambos casos, se explica la importancia de los hogares de dos personas, e incluso, en menor medida, de tres. Por el contrario, la alta proporción de personas mayores minusválidas que viven solas, en la mayor parte de los casos mujeres viudas, con un grado de independencia mucho más arraigado que el de los hombres y con la voluntad de permanecer en sus casas y no ser una carga para los hijos, reciben los únicos apoyos de aquellos familiares más próximos físicamente o de vecinos y amigos con los que mantienen estrechos vínculos, sobre todo en los núcleos rurales, destacando también la importancia relativa que para este colectivo tienen las ayudas y las asistencias sociales. 
Volviendo al caso de la población minusválida menor de 65 años, como se puede apreciar en el cuadro número 8 , la mayor parte de los cuidadores se erigen también en sustentadores de la economía doméstica (41.290 personas). En su mayoría se trata de cónyuges que además de atender a sus parejas discapacitadas desempeñan un trabajo remunerado fuera del hogar. El elevado número de cuidadores inactivos (40.408), por su parte, debe relacionarse con el hecho de que entre la población joven y adulto-joven soltera la asistencia personal viene de las madres, la mayor parte de ellas sin empleo fuera del hogar dada su función de "ama de casa", dejando a su pareja la responsabilidad de los ingresos familiares. En lo concerniente a la población discapacitada mayor de 65 años el peso de la inactividad laboral (169.043 cuidadores) se debe de una forma generalizada a la importancia que adquieren las pensiones, tanto del propio minusválido, que sustenta el hogar donde reside la hija soltera que se ocupa de sus cuidados, como en los casos en que las atenciones provienen del cónyuge jubilado.

Cuadro 8. Personas con alguna discapacidad y relación con la actividad laboral del cuidador principal

\begin{tabular}{lrrrrr}
\hline $\begin{array}{l}\text { Grupos de } \\
\text { edad }\end{array}$ & $\begin{array}{r}\text { Total per- } \\
\text { sonas con } \\
\text { alguna dis- } \\
\text { capacidad }\end{array}$ & $\begin{array}{r}\text { Total cui- } \\
\text { dadores ac- } \\
\text { tivos }\end{array}$ & $\begin{array}{r}\text { Cuidadores } \\
\text { trabajando }\end{array}$ & $\begin{array}{r}\text { Cuidadores } \\
\text { Parados }\end{array}$ & $\begin{array}{r}\text { Total cuida- } \\
\text { dores } \\
\text { Inactivos }\end{array}$ \\
\hline$<65$ años & 84.212 & 43.805 & 41.290 & 2.515 & 40408 \\
$>65$ años & 191.087 & 22.044 & 21.119 & 925 & 169.043 \\
\hline Totales & 275.299 & 65.849 & 62.409 & 3.440 & 209.451 \\
\hline
\end{tabular}

FUENTE: I.N.E.: Encuesta sobre discapacidades, deficiencias y estado de salud, 1999.

Cuadro 9. Personas con alguna deficiencia que han cambiado su relación con la actividad como consecuencia de discapacidad. 1999

\begin{tabular}{lrrr}
\hline & Varones & Mujeres & Total \\
\hline De trabajando a parado & 1.222 & 259 & 1.481 \\
De trabajando a inactivo & 9.979 & 4.803 & 14.782 \\
De parado a inactivo & 126 & 22 & 148 \\
Otro tipo de cambio & 447 & 309 & 756 \\
No consta & 2.160 & 486 & 2.646 \\
\hline Total & 13.934 & 5.879 & 19.813 \\
\hline
\end{tabular}

FUENTE: I.N.E.: Encuesta sobre discapacidades, deficiencias y estado de salud, 1999.

Finalmente, y como un factor inequívoco de la calidad de vida y de las oportunidades del colectivo analizado, en particular el de las personas menores de 65 años, hay que hacer referencia a las consecuencias sociolaborales de la dis- 
capacidad (CUADRO 9). Así, de las 19.813 personas para las que se dispone de datos, el mayor número, 14.782, han pasado de estar empleadas a ser consideradas inactivas, beneficiarias de una pensión por minusvalía. Otras 2.646 personas no han sufrido ningún tipo de cambio de actividad, no ocurriendo lo mismo para 1.481 que sí han perdido su puesto de trabajo.

\section{Una limitada e incipiente protección social: medidas de integración y atención pública.}

Para tratar de cubrir estos y otros desajustes que hacen difícil la inserción y con el objetivo de hacer efectivo el derecho a vivir en una sociedad más justa, más igualitaria, en la que los ciudadanos no se vean discriminados por situaciones que les vengan sobre impuestas como la discapacidad, los servicios sociales junto con las prestaciones de carácter económico (pensiones) constituyen los sistemas públicos de protección social competentes en la cobertura de necesidades específicas ${ }^{6}$.

\section{a. Los servicios sociales y la atención a personas con discapacidad.}

En 2001 se ha puesto en marcha el Tercer Plan Regional Sectorial de Atención a las Personas con Discapacidad ${ }^{7}$, que contó en su primer año de vigencia con un presupuesto de 61.793.017 euros. Su finalidad es el desarrollo de acciones encaminadas a conseguir la igualdad de oportunidades y la plena participación de las personas con discapacidad en todos los ámbitos sociales, culturales y laborables con vista a garantizarles la calidad de vida. Para su consecución las actuaciones se organizan en una serie de programas: valoración y diagnóstico de minusvalía, atención temprana y tratamiento, integración en la vida económica, apoyo a familias, accesibilidad, integración comunitaria, residencias y centros de día, subvenciones, formación y sensibilización.

A través de los Centros Base de Atención a Minusválidos se lleva a cabo la valoración, diagnóstico y orientación de las personas con discapacidad, 100.346 personas entre 1996 y 2001. Se atiende, además, a los que tienen reconocido un grado de minusvalía igual o superior al $33 \%$ o están en riesgo de padecerla. Para ello cuentan con los servicios de fisioterapia, logopedia, psicomotricidad, es-

\footnotetext{
${ }^{6}$ La organización de los servicios sociales en Castilla y León se fundamenta en la Ley 18/98, de 28 de diciembre, de Acción Social y Servicios Sociales de Castilla y León. Siendo competencia de la Gerencia de Servicios Sociales, organismo autónomo de carácter administrativo adscrito a la Consejería de Sanidad y Bienestar Social (en la actualidad a la Consejería de Familia e Igualdad de Oportunidades), la articulación, desarrollo y gestión de todas las acciones en materia de acción social y servicios sociales en la Comunidad Autónoma de Castilla y León.

${ }^{7}$ Aprobado por Decreto 266/2000, de 7 de diciembre (Junta de Castilla y León, 2001).
} 
timulación precoz y, en algunos casos, de psicoterapia, haciéndose especial hincapié en los niños menores de 6 años dentro del Programa de Atención Temprana. En total, se han beneficiado 779 personas, algunas de ellas con más de una deficiencia.

Aparte de los tratamientos realizados directamente en los Centros de Base ubicados en las capitales provinciales, los Programas de Atención Temprana se van ampliando progresivamente a través de acuerdos con ayuntamientos y convenios de colaboración con entidades privadas sin ánimo de lucro. Con este sistema se pretende atender a la demanda no cubierta en los Centros por falta de capacidad para asumir todas las necesidades de la provincia, intentando además acercar el recurso al ciudadano prestando el servicio en las áreas rurales donde residen niños que están incluidos en el programa de Atención Temprana.

Como se ha visto, las familias tienen un papel relevante en la atención de las personas con discapacidad, así como en el abordaje y reducción de situaciones de crisis. Por este motivo uno de los programas en los que se ha prestado una especial relevancia es el de apoyo a las familias con discapacitados:

- Facilitando formación y orientación para la convivencia y la utilización de los recursos comunitarios.

- Potenciando la organización de la solidaridad de las familias mediante grupos de autoayuda.

- Fortaleciendo las relaciones entre las personas con discapacidad internadas en una institución y su familia a través de la escuela de padres.

- Arbitrando los recursos necesarios para facilitar la permanencia de las personas con discapacidad en su hogar y entorno comunitario: programas de respiro familiar (a través de estancias temporales, 43 plazas), ayudas técnicas y para adaptación de viviendas (943 beneficiarios).

- Firmando convenios para el desarrollo de programas de respiro (familiar) con asociaciones de personas con autismo (2), parálisis cerebral (2), padres de niños sordos (1), esclerosis múltiple (1).

- Con la línea de ayudas individuales para tratamientos de asistencia especializada ( 232 beneficiados) ${ }^{8}$.

Otro de los programas está destinado a facilitar el acceso de las personas con discapacidad a los espacios y los servicios públicos mediante la progresiva su-

\footnotetext{
${ }^{8}$ Véase Situación Económica y Social de Castilla y León en 2001, pág. 469.
} 
presión de las barreras físicas y de comunicación, así como proporcionar las ayudas técnicas necesarias para vivir de la forma más autónoma posible (CUADRO 11). Las acciones que se han llevado a cabo pueden resumirse en las siguientes:

- Implantación de la Tarjeta de Estacionamiento para personas con discapacidad, concediéndose, durante 2001, 330 tarjetas en municipios de menos de 20.000 habitantes y entregándose a las corporaciones locales de más de 20.000 habitantes 950 tarjetas.

- Concesión de ayudas individuales para favorecer la movilidad, la comunicación y la accesibilidad de las personas con discapacidad.

- Colaboración con las Federaciones de Asociaciones de Personas Sordas y la de Asociaciones de Padres y Amigos de los Sordos para los programas de intérprete de lengua de signos y profesionales de apoyo a la formación con conocimiento de lengua de signos.

- Subvenciones para la adquisición y adaptación de vehículos de transporte colectivo dirigidas a entidades privadas sin ánimo de lucro, que promueven actividades y prestan servicios destinados a mejorar la calidad de vida de las personas con discapacidad. En el año 2001 se han concedido un total de subvenciones a 60 vehículos en Castilla y León 9 .

Cuadro 10. Ayudas individuales dirigidas a la movilidad, accesibilidad y comunicación. 2001

\begin{tabular}{lr}
\multicolumn{1}{c}{ Concepto } & $\begin{array}{r}\text { Número } \\
\text { de ayudas }\end{array}$ \\
\hline Adquisición de sillas & 71 \\
Adquisición/adaptación de vehículos a motor & 97 \\
Obtención del permiso de conducir & 6 \\
Ayudas técnicas a la accesibilidad & 615 \\
Obras adaptación de viviendas & 149 \\
\hline Total & 938 \\
\hline FuENTE: C.E.S. Castilla y León. Situación económica y social de Castillay \\
León en 2001.
\end{tabular}

Con respecto a la línea de apoyos técnicos y económicos para el fomento del asociacionismo y la participación social de las personas con discapacidad, se colabora con la Fundación Tutelar Castellano Leonesa de Deficientes Mentales, de manera que en el ejercicio 2001 dicha entidad tiene asumida la tutela de 104

\footnotetext{
${ }^{9}$ Igualmente en Situación Económica y Social de Castilla y León en 2001, pág. 469.
} 
personas con retraso mental residentes en Castilla y León que carecen de familia. También se ha apoyado con este programa a 204 personas universitarias con discapacidad (70 alumnos de la Universidad de Valladolid y otros 134 de la Universidad de Salamanca).

Cuadro 11. Plazas residenciales y centros de día según la entidad. 2001

\begin{tabular}{lrr}
\hline \multicolumn{1}{c}{ Entidad dependiente } & $\begin{array}{r}\text { Plazas } \\
\text { residenciales }\end{array}$ & $\begin{array}{r}\text { Plazas de } \\
\text { centro de día }\end{array}$ \\
\hline Gerencia de Servicios Sociales (centros propios) & 777 & 1.059 \\
Entidades locales & 680 & 853 \\
Entidades privadas sin ánimo de lucro & 1.819 & 3.340 \\
\hline Total & 3.286 & 5.252 \\
\hline
\end{tabular}

FUENTE: C.E.S. Castilla y León. Situación económica y social de Castilla y León en 2001.

En otro orden de cosas, desde la creación de la Gerencia de Servicios Sociales, se viene realizando un notable esfuerzo para incrementar las plazas en centros para personas con discapacidad. Por una parte, procurando ofrecer un servicio de vivienda o residencia temporal o permanente a personas con discapacidad que, por razones sociales o familiares, tengan dificultades para vivir en el domicilio o que necesiten de estos servicios para acceder a otros de recuperación o rehabilitación (es el caso fundamentalmente de los residentes en núcleos rurales, carentes de los recursos específicos necesarios). Por otra parte, a través de los centros de día permitiendo a las personas con discapacidad su desarrollo personal y su integración en la Comunidad (CUADRO 12).

También se mantiene relación con la Federación de Asociaciones pro Deficientes Psíquicos de Castilla y León (FEAPS), lo cual implica colaboración económica para el mantenimiento de las plazas residenciales y de centro de día, y para definir cuál va a ser el futuro de la acción conjunta para mejorar la calidad de vida de las personas con discapacidad. Esta colaboración económica para 2001 fue de 1.502.530,26 euros.

Por último, se han concedido subvenciones, dirigidas a ayudar a las personas con discapacidad, a las entidades privadas sin ánimo de lucro y entidades locales que atienden a estas personas y que están desarrollando programas para su integración social y laboral. Estas subvenciones ascendieron en 2001 a un total de 15.353.601,17 euros.

\section{b. Las prestaciones económicas.}

En el Sistema de la Seguridad Social se denominan pensiones a las prestaciones económicas periódicas vitalicias o de duración indeterminada. Entre las cla- 
ses de pensiones contributivas se encuentran las de Incapacidad Permanente. Éstas son las pensiones percibidas por los trabajadores que, después de haber estado sometidos a los tratamientos prescritos y de haber sido dados de alta médica, presentan reducciones anatómicas o funcionales graves, susceptibles de determinación objetiva y previsiblemente definitiva, que disminuyan o anulen su capacidad laboral.

Cuadro 12. Importe medio de las pensiones contributivas en Castilla y León y en España. 2001 (en euros)

\begin{tabular}{lrr} 
& España & Castilla y León \\
\hline Incapacidad permanente & 577,29 & 601,08 \\
Jubilación & 568,69 & 539,66 \\
Viudedad & 350,68 & 341,02 \\
Orfandad y favor familiar & 212,38 & 230,93 \\
\hline Total & 497,89 & 480,94 \\
\hline
\end{tabular}

FUENTE: C.E.S. Castilla y León. Situación económica y social de Castilla y León en 2001.

En Castilla y León el número de pensiones contributivas en el año 2001 fue de 565.000, de las cuales 42.300 , el 7,49\%, corresponden a prestaciones por incapacidad permanente, siendo el importe medio de estas pensiones de 601,08 euros, un $4,12 \%$ más alto que la cuantía media para el conjunto de España que se sitúa en 577,29 euros, por encima en ambos casos de la media del conjunto de pensiones contributivas, 497,89 y 480,94 euros en España y en Castilla y León respectivamente (CUADRO 13).

En cuanto a las pensiones no contributivas de jubilación e invalidez, que son aquellas prestaciones económicas periódicas, dirigidas a quienes reuniendo los requisitos de edad, residencia, ingresos y en su caso, incapacidad, no pueden acceder a las pensiones contributivas por no haber cotizado a la Seguridad Social o haberlo hecho por tiempo insuficiente, la Gerencia de Servicios Sociales ha gestionado en 200110.370 .549 euros, beneficiándose con ello a 28.815 pensionistas castellanos y leoneses. De estas 28.815 pensiones, 14.915 corresponden a las de jubilación (52,13\%) y 13.693 a las de invalidez (47,86\%), siendo la cuantía media mensual de las pensiones de jubilación de 265,13 euros y de las pensiones de invalidez permanente de 310,69 euros.

Finalmente, las prestaciones económicas y sociales previstas en la Ley de Integración Social del Minusválido (LISMI) beneficiaron en 2001 a 7.928 minusválidos castellanos y leoneses (CUADRO 14), habiéndose gestionado por parte de la Gerencia de Servicios Sociales el pago de 17.563.300 euros.

La cuantía de las pensiones no ha sufrido modificación alguna desde 1992, estando fijada en 149,86 euros al mes en concepto de subsidio de garantía de in- 
gresos mínimos y 58,45 euros por la ayuda de tercera persona en los casos que tengan reconocido este derecho. El subsidio de movilidad y compensación por gastos de transporte se revaloriza anualmente estando fijado para 2001 en 40,21 euros.

Cuadro 13. Prestaciones por LISMI. 2001

\begin{tabular}{lrr}
\hline Provincia & $\begin{array}{r}N^{\circ} \text { beneficiarios } \\
\text { a } 31 \text { de }\end{array}$ & $\begin{array}{r}\text { Importe total } \\
\text { anual (euros) }\end{array}$ \\
\hline Ávila & 549 & 1.204 .646 \\
Burgos & 532 & 1.174 .447 \\
León & 1.526 & 3.359 .741 \\
Palencia & 623 & 1.352 .550 \\
Salamanca & 1.722 & 3.750 .510 \\
Segovia & 537 & 1.237 .029 \\
Soria & 421 & 947.727 \\
Valladolid & 967 & 2.214 .921 \\
Zamora & 1.051 & 2.321 .729 \\
\hline Total & 7.928 & 17.563 .305 \\
\hline
\end{tabular}

FUENTE: C.E.S. Castilla y León. Situación económica y social de Castilla y León en 2001.

\section{CONCLUSIONES}

Casi seis de cada cien personas que habitan la Comunidad son discapacitadas. Un hecho que debe relacionarse, en primera instancia, con el rasgo demográfico fundamental que caracteriza a Castilla y León: el envejecimiento de su población. Una relación, entre vejez y discapacidad, todavía más estrecha habida cuenta de la particular estructura por edades de la población minusválida, con casi diecisiete personas mayores por cada joven, lo que explica que haya 0,83 hombres por cada mujer discapacitada, que los mayores porcentajes de deficiencias se asocien a tipos de minusvalías físicas y psíquicas, y que la mayor proporción de castellanos y leoneses que presentan alguna discapacidad vivan en municipios rurales, precisamente aquellos en los que el envejecimiento se presenta de manera especialmente significativa.

La mayor o menor calidad de vida de estas más de 145.000 personas discapacitadas está condicionada por la convivencia en un entorno más o menos afectivo. En este sentido, la estructura de los hogares por tamaño predominante es la de dos personas, siendo la forma de convivencia dominante entre las personas minusválidas dependientes: la de pareja. Además, es el compañero o compañera el que se erige también en sustentador de la mayoría de las economías domésticas. Dependencia económica que se vincula, en buena medida, con el peso de la 
inactividad laboral (de las 19.813 personas para las que se dispone de datos 14.782 han pasado de estar empleadas a ser consideradas inactivas) y a la importancia que adquieren las pensiones.

Para tratar de cubrir estos y otros desajustes que hacen difícil la inserción y con el objetivo de hacer efectivo el derecho a vivir en una sociedad más justa, más igualitaria, en la que los ciudadanos no se vean discriminados por situaciones que les vengan sobreimpuestas como la discapacidad, en 2001 se ha puesto en marcha el Tercer Plan Regional Sectorial de Atención a las Personas con Discapacidad. Los principales programas se centran en la atención en los Centros Base, en el apoyo a las familias con discapacitados y en el incremento de las plazas en centros para personas con discapacidad.

El desarrollo de todas las actuaciones contempladas en este Plan, de consuno con las cada vez más importantes prestaciones económicas (pensiones de Incapacidad Permanente, las no contributivas de invalidez y las previstas en la Ley de Integración Social del Minusválido), hace que se pueda albergar cierta esperanza en alumbrar, en un futuro más o menos próximo, un horizonte en el que las personas discapacitadas tengan cubiertas gran parte de sus necesidades sociales.

\section{FUENTES}

InSTITUTO NACIONAL De ESTADÍSTICA: Revisión del Padrón de Habitantes a 1 de enero de 1999.

InSTITUTO NACIONAL DE ESTADÍSTICA: Encuesta sobre Discapacidades, Deficiencias y Estado de salud, 1999.

JunTa De CAstilla Y LeÓn: Base de Datos de Reconocimiento de Minusvalía, 1999.

MINISTERIO DE TRABAJO Y ASUNTOS SOCIALES (INSTITUTO DE MigRACIONES Y SERVICIOS SOCIALES): Base Estatal de Personas con Discapacidad, 1999 y 2001.

Universidad De SALAmanca (SERVicio De Información Sobre DISCAPACIDAD): Estadísticas varias sobre discapacidad y empleo.

\section{BIBLIOGRAFÍA}

CABALLERO FERNÁNDEZ-RUFETE, P. (2002): «Población rural y estructuras demográficas en Castilla y León», en BLANCO MARTíN, A.: Envejecimiento y mundo rural en Castilla y León. Madrid, Estudios de la Fundación Encuentro y Caja España, págs 63-109.

CABAllero Fernández-Rufete, P. y Delgado UrRecho, J. Ma. (dirs.) (2003): La situación de las personas mayores en Castilla y León. Valladolid, Consejo Económico y Social de Castilla y León, 219 págs. 
FERNÁNDEZ-MAYORALAS, G., ABELLÁN GARCÍA, A., RodRÍGUEZ RodRÍGUEZ, V. y ROJO PÉREZ, F. (1993): «Desigualdades en salud y envejecimiento demográfico», Anales de Geografía de la Universidad Complutense, núm. 13, págs. 139-154.

JunTa De CAstilla Y León (2001): Plan Regional Sectorial de Atención a las Personas con Discapacidad. Valladolid, Consejería de Sanidad y Bienestar Social, Gerencia de Servicios Sociales, 150 págs.

LÓPEZ TRIGAL, L. y DELGADO URRECHO, J.Mª (dirs.) (2002): La población inmigrante en Castilla y León. Valladolid, Consejo Económico y Social de Castilla y León, 143 págs.

ORTEGA VALCÁRCEL, J. (2000): Los horizontes de la Geografía. Barcelona, Ariel, 604 págs.

VV.AA. (2002): Situación Económica y Social de Castilla y León en 2001. Valladolid, Consejo Económico y Social de Castilla y León, 603 págs. 